\title{
The poisonous potency of script: Hindi and Urdu
}

\author{
ROBERT D. KING
}

\section{Abstract}

Hindi and Urdu are variants of the same language characterized by extreme digraphia: Hindi is written in the Devanagari script from left to right, Urdu in a script derived from a Persian modification of Arabic script written from right to left. High variants of Hindi look to Sanskrit for inspiration and linguistic enrichment, high variants of Urdu to Persian and Arabic. Hindi and Urdu diverge from each other cumulatively, mostly in vocabulary, as one moves from the bazaar to the higher realms, and in their highest - and therefore most artificial — forms the two languages are mutually incomprehensible. The battle between Hindi and Urdu, the graphemic conflict in particular, was a major flash point of Hindu/Muslim animosity before the partition of British India into India and Pakistan in 1947.

\section{Introduction}

Hindi and Urdu are so similar in their marketplace spoken forms that no linguist would hesitate to classify them as near dialects of the same language - based on their common spoken varieties. Hindi and Urdu are among the first languages to be cited in general discussions of the topic of digraphia. In the linguistic literature one finds Hindi-Urdu the convention is to hyphenate "Hindi" and "Urdu" — cited both as a "typical" case of digraphia and as an "extreme" case of digraphia. It is easy to make a convincing case for either characterization.

There is a prodigal visual difference between the Devanagari script (also called Nagari) used to write Hindi and the Perso-Arabic script ordinarily used to write Urdu. The Devanagari script of Hindi is "squarish," "chunky," "has edges" — conventional characterizations all - written left to right, with words set off from each other by an 


\section{R. D. King}

overhead horizontal line connected to the graphemes and running from the beginning of the word to its end. The Perso-Arabic script of Urdu is "graceful," "flowing," "has curves," written right to left, with word boundaries marked as much by final forms of consonants as by spaces. The immediate visually iconic associations are: Hindi script=India, South Asia, Hinduism; Urdu script= Middle East, Islam. The graphemic difference between Hindi and Urdu is far more dramatic, for example, than the difference between the Cyrillic script of Serbian and the Roman script of Croatian.

If in one sense the case of Hindi-Urdu is extreme in the annals of digraphia, in another it is typical, for when is digraphia ever simply a case of "digraphia" pure and simple? - a graphemic substitution, as if a single language $\mathrm{L}$ were enciphered by one group of its users in a script $\mathrm{S}_{1}$ and by a second group in a script $\mathrm{S}_{2}$, without ancillary distinctions. The script differences in "typical" cases of digraphia almost always mask profound differences both linguistic and societal: in grammar and vocabulary, in cultural orientation and often in religious orientation as well, in history, in style and preferences for different literary genres, in way of life and sensibility. Digraphia is not unlike the proverbial ten percent of an iceberg that is visible above the water: the part that is visible - the script - is the least of it.

Finally there is the matter of the extralinguistic correlates of HindiUrdu digraphia - of digraphia as a cause of violence - in Indian history often even as an excuse for violence. One can easily imagine a condition of pacific digraphia: people who speak more or less the same language choose for perfectly benevolent reasons to write their language differently; but these people otherwise like each other, get on with one another, live together as amiable neighbors. It is a homey picture, and one wishes it were the norm. It is not. Digraphia is regularly an outer and visible sign of ethnic or religious hatred. Script tolerance, alas, is no more common than tolerance itself. In this too Hindi-Urdu is lamentably all too typical. People have died in India for the Devanagari script of Hindi or the Perso-Arabic script of Urdu. It is rare, except for scholars, for Hindi speakers to learn to read Urdu script or for Urdu speakers to learn to read Devanagari.

\section{Historical synopsis}

Hindi and Urdu are closely related languages, both derived from Sanskrit and both members of the Indo-Iranian branch of Indo-European (see Cardona 1987a; Chatterji 1969; Dittmer 1972; Kachru 1987; 
Kelkar 1968; C. King 1994: 4-52). Sanskrit, originally the language of the sacred texts of Vedantic or Hindu India ${ }^{1}$ (the Vedas, the Mahabharata, the Ramayana) and the major regional language of northern India in the "classical period" (around 300 B.C.E.), was the language of the descendants of the Indo-Aryans who had invaded India from the northwest, displacing and driving southward an autochthonous population consisting mostly of Dravidians. The date conventionally given for the arrival of the Indo-Aryans is around 1500 B.C.E., though it could well have been earlier (Kulke and Rothermund 1993: 33-35; Wolpert 1993: 24-27). Sanskrit diversified regionally into the languages known as the Prakrits, from which the major languages of northern and central India derive: Bengali, Marathi, Gujarati, and Oriya, as well as Hindi and Urdu. Both Hindi and Urdu evolved from Khari Boli, a branch of Western Hindi (Madhyadeshi) spoken in the region of northern India known as Haryana, which includes the present-day capital of India, Delhi. $^{2}$

Hindi has a relatively young literary tradition within India, being customarily dated to around 1800 (cf. Kelkar 1968: 16 [foldout]; Chatterji 1969, especially part II, lectures II and III; also Kachru 1987). Urdu literature is only slightly older (there are serious problems dating either literature; cf. C. King 1994: 24). Compared with Bengali literature, or Tamil, Kannada, or Telugu literature, or indeed almost any Indian literature, Hindi-Urdu literature is quite young.

The traditions and usages of India were put in place between 500 B.C.E. and 500 C.E. The first important dynasty of which we have reliable knowledge was the Mauryan empire, whose greatest ruler, Ashoka, gained the throne in 268 B.C.E. Mauryan culture was Hindu through and through, though Ashoka himself probably adopted Buddhism. His conversion - if that in fact is what it was, the record is not completely clear - to Buddhism means less than it might seem, for Buddhism arose as a reform movement within Hinduism much as did other religions such as Christianity and Protestantism.

Following Ashoka's death the Mauryan empire went into decline, and after a dark-age period of several centuries another gifted ruler arose to command most of the country. This was Chandragupta I (320 to about 335 C.E.), founder of what came to be known as the Guptan dynasty, like the Mauryans also Hindu in religion and culture. Chandragupta's patronage of the arts and literature ushered in what is called the "Golden Age" of Sanskrit literature - even though by this time Sanskrit had long been supplanted by the Prakrits vernaculars as the everyday spoken languages of northern India. But Sanskrit continued as the ritual language of religious ceremonies and high culture and continues to some 
extent into the present as a spoken language among pandits and Sanskrit devotees.

Ashoka issued numerous decrees expounding his philosophy and regulating the conduct of his subjects. He "published" these decrees in an abundance of edicts carved on rocks and pillars throughout the expanse of his empire and even outside India. Ashoka's rock edicts are invaluable to the linguistic historian, for they contain the earliest evidence of Indian script.

Two scripts were used for writing Sanskrit, Brahmi and Kharoshthi, which, because they are fully developed at the time of Ashoka's edicts (his reign lasted from 268-238 B.C.E.), we assume originated earlier, perhaps in the fifth century B.C.E. (Kulke and Rothermund 1993: 53). Kharoshthi, written from right to left, was used predominantly in the northwest, Brahmi, written from left to right, elsewhere (Cardona 1987a: 441). Script in India was almost certainly invented under Persian influence. The Persians controlled the northwest of the Indian subcontinent at that time, and the Kharoshthi script seems to have been based on the Aramaic script used as the official script of the Persian empire (Kulke and Rothermund 1993: 54; Wolpert 1993: 62). Most of the scripts used for writing the modern Indo-Aryan languages derive from the Brahmi script of Sanskrit, and this includes Devanagari ("City of the Gods") which is the script of Hindi as well as Marathi and Nepali.

Arab traders began traveling to India as early as the seventh century C.E. The riches and stories they returned with whetted the appetites of the more adventurous of their coreligionists, and by the tenth century Turko-Afghan Muslims were regularly invading northwest India in search of plunder and converts. By the thirteenth century Muslims were in control of most of northern India, and three centuries later the (Muslim) Mughal dynasty ruled with an iron hand all of north India down well into the Deccan (the Deccan plateau cuts a swath from west to east through central India). The impact of Mughal rule, its greatest emperor Akbar (1542-1605) in particular, on the course of Indian history and on all aspects of Indian culture was enormous - and fateful.

Part of the historic legacy of that impact was linguistic and graphemic. Urdu arose as the everyday language of the Mughal Empire, whose official and administrative language was Persian. Urdu was the language of the princely courts such as Delhi and Lucknow. The designation "Urdu" is not found until 1752, when the poet Mir gave it the name Urdu$e$-Mu'alla 'courtly language' (Dittmer 1972: 48). The word 'Urdu" is of Turkish origin (ordu) and originally meant 'camp'. Thus Urdu arose essentially as "the language of the (army) camp." Because of its Mughal and therefore Islamic provenance Urdu had by 1600 C.E. diverged from 
its Hindi origins through extensive absorption of Persian and Arabic linguistic material: loan words, syntactic turns of phrase, a handful of phonemes borrowed from Persian, a certain precious "courtly style," a Persian cast to poetry and song. The ghazal, for example, a genre of song much admired in India by Hindus and Muslims alike, is Persian in origin.

It must be remembered that from roughly 1400 C.E. onward Persia was to those countries in its cultural orbit what France was to Europe during the reign of Louis XIV, and for a long time afterward. Persian ways set the tone in the ruling courts of Turkey, Afghanistan, and northern India. Persian culture and cuisine were highly valued. The Persian language was the language of diplomacy, of treaties, of art and beauty, of song, of love. Even after the British had assumed control of most of India, moving into a political vacuum created by the shrinking of the Mughal dynasty, they continued the use of Persian as the language of administrative records until the 1830s, when English became the official language of the Raj. The Persian language maintained a "high" function in Indian Muslim life long after it had ceased to be anybody's first spoken language there. A favorite diversion - opium was another of the last Nizam of Hyderabad, a Muslim-ruled enclave in the Deccan, whose reign was ended in 1948, was composing quatrains in the Persian language. His native language was of course Urdu.

It was only natural in so Muslim a culture as that of the Mughals that Urdu would have been written from its earliest days onward in a variant of the Arabic script - unsuited as such a script is to any Indo-European language. Education in Muslim countries always laid heavy emphasis on religion - on the Qur'an [Koran], written in classical Arabic - and to be literate has meant to be literate in Arabic. For traditional and religious reasons, therefore, most languages spoken in Muslim countries adapted versions of the Arabic writing systems to their languages when they developed writing systems. This was done whether the language in question was actually suited to be written in a Semitic-based script or not. Thus, Persian and Urdu - Indo-European languages both, not Semitic - are written in scripts based on Arabic, as was the Turkish (called "Osmanlica") of the Ottoman Empire, as was Swahili, a Bantu language, when its east African homeland was under Arab/Islamic hegemony. Neither Turkish nor Swahili belongs to the Indo-European family of languages. (Today both Turkish and Swahili are written in romanized scripts.)

Semitic languages such as Arabic and Hebrew are organized around the principle of the root: roots have a basic meaning expressed by means of, usually, three consonants. The Semitic root SLM elucidates the principle. Its basic, abstract meaning is 'peace', and from it are derived 
such words as Arabic SaLaaM - the greeting (in essence "peace be with you', cf. Hebrew ShaLoM). Consider also iSLaM and ( $m$ ) uSLiM and the proper names from Jewish history such as (Hebrew) $\operatorname{SoLoM(on)}$ and SaLoMe or (Arabic) SuLeiM(an). The reader of Arabic or Hebrew recognizes that the basic "meaning" of the word or name is carried by the root structure SLM. The common semantic intersection of these and other words formed with the three consonants SLM is 'peace'.

Normally Semitic words are written without vowels. This is possible because the context suggests the range of readings of a given word in print and because there are rules of grammar - morphological rules normally - that help the reader know what vowel is to be supplied. In Hebrew, for example, the word spr consisting of three letters can be read /safar/'he counted', /siper/'he told', /supar/'it was told', /sapar/'barber', /sefer/'book', and /sfar/'frontier' (Rabin 1971: 97). (In Hebrew the same letter is used for $/ \mathrm{p} /$ as for /f/.) "Full spelling," in which diacritic marks are used to indicate the vowel, can be used in Hebrew or Arabic but normally is not, at least not for adult readers of the language. The reader simply has to know from context and native linguistic knowledge of the language which reading is the correct one.

This vowelless scheme works for Semitic languages because of the semantic centrality of the root. It does not work at all well for writing languages not in the Semitic family. No speaker of English would be happy having to make sense of a sentence written ths artcl dls wth dgraph $n$ hnd $n d r d$. No rules help the English-literate supply the missing vowels.

\section{Grapheme and phoneme}

Hindi and Urdu, like most languages of the subcontinent, are characterized by two specific Indian phonological phenomena: retroflexion, and aspiration of stops both voiceless and voiced. Retroflex stops [t d] are rare in the world's languages, as are voiced aspirated stops (unlike voiceless aspirated stops, which are common). Hindi and Urdu have the voiced aspirated stops [bh $\mathrm{dh} \mathrm{dh} \breve{\mathrm{j} h} \mathrm{gh}$ ] as well as voiceless aspirates [ph th th čh $\mathrm{kh}$. Also in both languages nasalization of vowels is phonemic, as in [ak] 'a plant' and [ãk] 'draw, sketch'.

The vowels /i/ and / $\mathrm{u} /$ occur both long and short. The long variants /i:/ and $/ \mathrm{u}: /$ are realized as tense [i] and [u] with vowel length; the short variants $/ \mathrm{i} /$ and $/ \mathrm{u} /$ are realized either as short [i] and [u] or as lax [I] and [U]. (I am adopting here the analysis of Kachru [1987: 472] with two exceptions: she classifies /r/ and /1/ as "alveopalatal," and I classify them 
as "dental.") The low vowel /a/ is realized as [ə] when short and [a] when long.

The segmental phonemes of Hindi-Urdu may be listed as follows:

Vowels

$\begin{array}{lccc} & \text { Front } & \text { Central } & \text { Back } \\ \text { high tense } & \text { i } & & \text { u } \\ \text { high lax } & \text { I } & & \text { U } \\ \text { mid tense } & \text { e } & & \text { o } \\ \text { mid lax } & \varepsilon & \text { o } & 0 \\ \text { low } & & \text { a } & \end{array}$

Consonants

Labial Dental Retro- Palato- Velar Uvular

flex alveolar

vl.

$\begin{array}{llllllll}\text { unaspirated } & \mathrm{p} & \mathrm{t} & \mathrm{t} & \mathrm{c} & \mathrm{k} & \text { (q) }\end{array}$

stop

aspirated ph th th čh kh

$\mathrm{vd}$.

$\begin{array}{lllllll}\text { unaspirated } & b & d & d & \breve{j} & g\end{array}$

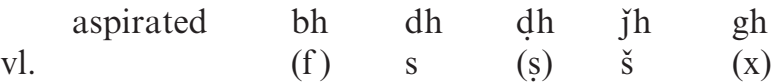

fricative

vd.

(z)

$(\check{\mathrm{z}}) \quad(\mathrm{\gamma})$

flap

unaspirated

r r

vd.

aspirated

ṛh

lateral

nasal

glide

$\begin{array}{lllll}\mathrm{m} & \mathrm{n} & \{\mathrm{n}\} & \{\tilde{\mathrm{n}}\} & \{\mathrm{n}\} \\ \mathrm{w}(\mathrm{v}) & & & \mathrm{y} & \mathrm{h}\end{array}$

The sounds enclosed in parentheses ( $\mathrm{q} f \mathrm{~s}$ x z ž $\mathrm{\gamma}$ ) were originally borrowed from Persian and tend to occur in highly Persianized variants of Urdu. The sounds enclosed in curly brackets $\left\{\begin{array}{lll}n & \tilde{n} & y\end{array}\right\}$ are used in highly Sanskritized variants of Hindi (about which I shall have more to say later).

The script used for writing Urdu was derived from the Persian script, itself an adaptation of the Arabic script, hence my references throughout to the "Perso-Arabic" script of Urdu. Actually two versions of what I am calling the "Perso-Arabic" script of Urdu are used in India and Pakistan, as well as in other languages using Arabic script or variants of 
the Arabic script. The more common of the two is called nastaliq. An alternative form called nashkh is also employed to write Urdu. The main difference is that in nastaliq words slant diagonally - from northeast to southwest as it were - from the top of the line to the bottom whereas in nashkh words run along the bottom line more horizontally with less of an above-baseline slant. Whatever the differences between nastaliq and nashkh - and they are not great - they are trifling against the difference between either of them and Devanagari. (A very useful reference for this is the little "Lonely Planet" Hindi and Urdu Phrasebook [Delacy 1998].)

While the graphemic fit of the Devanagari script to the phonemics of Hindi-Urdu is very good, that of the Perso-Arabic script in either of its variants is poor. The script is extremely deficient in the vowel category no surprise, since Arabic has no graphemes for vowels. The same symbol is used to spell $/ \mathrm{a} /, / \mathrm{i} /, / \mathrm{u} /, / \mathrm{e} /, / \mathrm{o} /, / \varepsilon /$, and $/ \mathrm{o} /$. Diacritics are available to differentiate the vowel qualities, but they are not often used except for children and beginners in the language. As for the consonants, Urdu "has an overabundance of consonant symbols" (Kachru 1987: 475). This is true provided the full set of diacritic marks normatively specified for writing Urdu is employed, which is not always the case. For example, the same basic symbol is used to denote the phonemes $/ \mathrm{p} /, / \mathrm{b} /, / \mathrm{t} /$, and $/ \mathrm{t} /$, and diacritics are added to differentiate them. The same is true for other sets of sounds such as $/ \mathrm{s} /, / \check{\mathrm{s}} /, / \mathrm{sv} /, / \mathrm{z} /$, the stops $/ \mathrm{k} /, / \mathrm{q} /$, and $/ \mathrm{j} /, / \check{\mathrm{c}} /, / \mathrm{h} /, / \mathrm{x} /$. If the diacritics are omitted, then the writing system is underdifferentiated almost to the point of unreadability except for the most adept. One version of cursive Urdu script, shikasta, is so difficult to read that even people who use it have trouble reading it (the word shikasta means 'broken writing'; C. King 1994: 150, 165 n. 13). In one nineteenthcentury pro-Hindi, anti-Urdu language tract utilizing a brand of heavy humor difficult to gauge at this distance, "The Drama of the Boat and the Prostitute," a District Superintendant of Police sends a message in Urdu to one of his subordinates requesting that a boat (kishtī) be kept ready for his arrival. Because of the ambiguity of the Urdu script the subordinate misreads kishtī as kasbi 'prostitute', leading to embarrassing and amusing developments (C. King 1994: 135).

The Devanagari script of Hindi does not treat retroflexion and aspiration as distinctive features. For example, /t/ and / $\mathrm{t} /$ are completely different graphemes, as are $/ \mathrm{b} /$ and $/ \mathrm{bh} /$. Urdu on the other hand deals with the two features graphemically in much the way a modern phonologist does - by marking retroflexion and aspiration as modifications of more basic sounds. Urdu script uses a diacritic mark for retroflexion, so that the retroflex sounds $/ t \mathrm{~d}$ r $r$ are written with the same basic graphemes as $/ \mathrm{t} \mathrm{r} /$ but marked with the diacritic for retroflexion. 
Aspiration is indicated in Urdu by adding an $h$, so that the graphemic contrast between $/ \mathrm{p} /$ and $/ \mathrm{ph} /, / \mathrm{b} /$ and $/ \mathrm{bh} /$ and so on is marked by adding $h$ to the aspirated member of each pair of sounds. Hindi marks nasalization of vowels by a symbol called candrabindu - which resembles the nose and mouth of a "smiley-face" — above the vowel. Urdu indicates nasalization by using the letter nun $/ n /$.

\section{Higher correlates of Hindi-Urdu digraphia}

I said earlier that digraphia is almost never digraphia pure and simple. While the script difference between Hindi and Urdu is extreme, no less extreme are differences in the "higher" regions of vocabulary, grammar, and style. Kelkar (1968: 6-7) has summarized the sociolinguistic situation, and I quote him here at length:

[A]s a linguistic system Hindi-Urdu [which Kelkar calls "Hirdu"; I prefer "HindiUrdu"] has no marked dialect variations; but it has the full gamut of styles ...: formalized highbrow (poetry, learned discourse, oratory, religious sermons and the like in the "great tradition" 3 of urban centers of power, commerce, and religion); formalized middlebrow (popular printed literature, songs, and films; ... mass propaganda); casual middlebrow (everyday educated talk especially in linguistically mixed groups and within the regionally uprooted upper or middle class family; private letter writing and newspapers waver between this and the previous styles; out of the four styles this is the most receptive to borrowings from English); and casual lowbrow (this is definitely substandard and outside the "Great Tradition"; everyday talk in lower-class, uneducated, urban milieus; this style, often called "Bazaar Hindustani" [bazaru hindustani], is sometimes resorted to even by educated speakers and even in printed literature destined for the uneducated lower classes) ... [The] polarization between "Hindi" and "Urdu" reaches its maximum in the formalized highbrow style. ... Hindi is associated with the Devanagari script (called Nagari for short) and the drawing upon Sanskrit for "higher vocabulary" and metrics, with secular nationalism and Hindu revivalism, and with what anthropologists have called "Sanskritization" [the spread of Vedantic and Brahmanical culture].... Urdu is associated with a modified form of the Perso-Arabic script and the drawing upon classical Persian (and through it, upon classical Arabic and upon Turkish) for "higher vocabulary" and metrics and with Muslim renascence and the courts of the Muslim princes.

The differences among the styles that Kelkar identifies have mostly to do with vocabulary rather than morphology or syntax. Common words like chai 'tea', milna 'to meet', and mashin 'machine' are the same in either Hindi or Urdu. Vocabulary diverges sharply as we move from Low to 
High. The Hindi words for 'south' and 'temperature' (as in weather) are dakshin and tapman, the Urdu words junub and darja-e-hararat. The sentence "Who is the prime minister at the moment?" is ajkal pradhan mantri kaun hai? in Hindi, ajkal vazir-e azam kaun hai? in Urdu (Delacy 1998: 100).

An Indian linguist has illustrated how far the styles deviate from each other by asking how the abstract expression "salvation's true path" might be translated into Hindi and Urdu at different style levels and among different ethnic-social groups (Ornstein and Gage 1964: 123). Village people would render this as mukti-ki sacci sarak (Bazaar Hindustani). Pandits or educated Hindus would say mukti-ki satya upay (Highbrow Hindi). Cultured Muslims would translate the phrase as nájat-ki haqq rah (Highbrow Urdu). Indians who speak English as their second language might say salweshan-ki tru path. The only indication that these four "languages" are in some sense variants of the same language is the genitive marker -ki. Words like satya and upay in the Highbrow Hindi rendering are from Sanskrit. Every single content morpheme in the Highbrow Urdu version is from Persian or Arabic. One sees how dramatically the character of a language is changed when the sources of borrowed words for new concepts are as far apart as they are in Hindi and Urdu: we might as well be dealing with different languages.

Standard (Highbrow) Hindi and standard (Highbrow) Urdu diverged even more startlingly after the partition of India into India and Pakistan in $1947 .{ }^{4}$ Partition was accompanied by appalling ethnic and religious violence, and virtually all Hindus and Sikhs fled to India from their homes in what had become Pakistan. Many, though far from all, Muslims fled to Pakistan. Thus the population of Pakistan is almost completely Muslim, and India is overwhelmingly Hindu in religion and culture. Nevertheless, with its approximately 10 percent Muslim population, India contains one of the largest Muslim populations in the world (India's population is approaching a billion). The present population of Pakistan is estimated to be $135,000,000$ (Kaplan 1999). Urdu is the national language of Pakistan, although most Pakistanis speak as their first language something else, such as Panjabi, Sindhi, or Pashto. The educational system is built around Urdu. Most but not all of the Muslims in India have Urdu as their first language.

After partition the two languages were freer to go their own way in their respective countries, Hindi in India and Urdu in Pakistan. The process of divergence was accelerated with the spread of radio and now television (Kelkar 1968: 17, note; Das Gupta and Gumperz 1968). Highbrow Hindi in India became more Sanskritized and more influenced 
by other Indo-Aryan languages such as Bengali. Urdu in Pakistan became even more Persianized than when it had had to coexist with Hindi in an often uneasy alliance. Under the new, increasingly Sanskritized Hindi that became fashionable among some elites after partition, the distance between the official rendering of a phrase and its rendering in colloquial educated style widened. The following illustrations are taken from one of the classic scholarly studies of the subject (Das Gupta and Gumperz 1968: 161). Items 1 and 2 are from signboards intended for the public. In both cases $a$ is the official text, which is strongly Sanskritized, $b$ is the English translation, and $c$ is an approximate equivalent in the colloquial educated style (Kelkar's Casual Middlebrow):

Item 1 a. dhumrpan varjint hai

b. smoking prohibited

c. sigret pina mana hai

Item 2 a. bina agya pravesh nishedh

$b$. entrance prohibited without permission

c. bina agya andar jana mana hai

Hindi-speaking Indians frequently say that they simply cannot understand the Urdu of Radio Pakistan; Urdu-speaking Pakistanis say the same of the Hindi heard on All-India Radio (Kelkar 1968: 17, note). A Pakistani tourist I met once in Agra (India) said that, although she normally spoke Urdu at home and therefore had thought she would have no trouble understanding the Hindi of Agra, it was easier for her to ask directions of Sikhs in India since they spoke Panjabi, which was her second language. The first prime minister of India, Jawaharlal Nehru, spoke Hindi - though for mostly political reasons he usually called it Urdu - as his first language, though schooling in England and a long involvement in Indian politics had made him far more secure in his English than in his Hindi-Urdu. Nehru frequently complained that he could not understand the increasingly Sanskritized Hindi language promulgated by All-India Radio. He commented on this in his letters, and on at least one occasion he rose in the Lok Sabha - lower house of the Indian parliament - to complain that he could not understand Hindi broadcasts of his own speeches (R. King 1998: 78).

Anyone who has ever been present during a conversation between an Urdu-speaking Muslim cleric and a Hindi-speaking secular intellectual will be familiar with the immense gulf of incomprehension that lies between them, only one aspect of which, of course, is linguistic. I was once part of a little group - in 1990 — that was guided on a walking tour of Old Delhi by an Indian architectural historian whose native language 
was Hindi. Old Delhi is still very much Muslim, no part of it ever very far from the muezzin's cries. Shop signs in Urdu are the rule. Much of the time our guide was engaged in conversation with Muslims on the street, asking directions and engaging in casual conversation. I detected no problems in his making himself understood and understanding what was said to him in return; both sides were speaking the language essentially of the street — Bazaar Hindustani — and at that level the differences between Hindi and Urdu do not signify. (Village India where even today most of India's population lives — was always indifferent to the Hindi-Urdu controversy. It was a concern of the urban elite.)

The tour culminated in a visit to the home of a Muslim cleric. He had lived in his section of Old Delhi for almost all of his long life (he was in his seventies) and was respected as a man of age, wisdom, and sanctity by his followers and neighbors. He was very gracious to our group a male Muslim student who spoke Urdu, the Hindi-speaking wife of a colleague, two Western women, me, and our guide - offering the hospitality of his home and trying to make everyone comfortable. Our guide, the Hindi-speaking secular Hindu architectural historian, asked questions of the cleric having to do with dates of events in that section of Old Delhi, when various houses and mosques had been built, when this mosque or that had ceased to be active places of worship, and much else in that vein.

At this level of discourse communication was just about impossible. The conversational strain was impossible to overlook, in spite of the best will in the world on both sides. There was to begin with the problem of dates: when did they decommission that mosque that used to be around the corner? The Muslim cleric dated events not in the "conventional" manner, that is, to say in 1956 or 1981 or whatever, but in the Muslim way: the first year of the Muslim era is 622 C.E., the year the Prophet left Mecca for Medina. The year 2000 C.E. in the Gregorian calendar is the Muslim year 1421.

The conversion of dates is difficult enough to make on paper, but almost impossible to do in the viva voce of uneasy conversation. Apart from the problem with dates, the architectural terminology was altogether different between Hindi and Urdu — specialized vocabulary usually is. The conversation was such that genuine communication was scarcely possible on any but the most mundane topics involving neither dates nor technical terminology. The situation was painful to endure, for both parties to the conversation had very much hoped to make this harmless and decent little instance of Hindu-Muslim-Western friendliness succeed. 


\section{The politics of Hindi-Urdu digraphia}

Hindi-Urdu digraphia became a part of the Indian freedom movement the movement led by Mohandas K. Gandhi to persuade the British to give India back to the Indians - as part of the question of the "national language": what should be the national language of India once independence had been gained? Practically speaking there is no language understood the width and breadth of India except English, but for understandable reasons nobody wanted to declare as the national language the very language of the rulers they proposed to throw out. Hindi-Urdu was the only language that had support as the national language, even though it was a north Indian language and never the first language of more than about 35 percent of the Indian population. (Christopher King's book One Language, Two Scripts [1994] gives an excellent account of the history of Hindi-Urdu language politics).

Until strife between Muslims and Hindus swamped Indian public life in the last generation of the British Raj, the juxtaposition Hindi: Urdu $=$ Hindu: Muslim did not evoke the immediate communal ${ }^{5}$ response that it does today and has since the turn of the century. Motilal Nehru, the father of Jawaharlal Nehru and a Hindu, spoke and wrote Urdu as his first language (C. King 1994: 16; R. King 1998: 78). The British had introduced Urdu in the Perso-Arabic script as the language of the courts and administration in the Northwestern Provinces after the Sepoy Mutiny in 1857, and Urdu was mandated as the language of the Indian army in 1864. British officials were in agreement that Urdu or, as they had begun to call it, Hindustani should become the lingua franca of all India, at least of north India. However, Hindi written in Devanagari script enjoyed greater popularity among the common people than Urdu in Perso-Arabic script (Dittmer 1972: 86-87).

In the nineteenth century the question of script became paramount. Organizations of writers, scholars, and intellectuals in general were created to argue for one script or the other. An extraordinarily large amount of political energy was expended on Hindi-Urdu digraphia as communal tensions between Hindus and Muslims increased (C. King 1994).

After Gandhi had returned to India from South Africa during the first World War, the independence movement began to gather steam. At the same time Hindu: Muslim distrust began to grow (for a discussion of the factors involved in this see R. King 1998: 80-81). Related to this was the fear among Muslims that Urdu and in particular its script were in danger of being supplanted altogether by Hindi. 
After 1920 the question of the national language moved to center stage, largely because Gandhi saw it as an opportunity to reassure Muslims of their security in a Hindu-majority free India. To Gandhi nothing mattered more, ever, than that Hindus and Muslims should live together in harmony in India. That was to him - though not to many of his followers - more important even than getting rid of the British. Gandhi himself was a native speaker of Gujarati, and by all accounts he knew little of the literary or linguistic backgrounds of either Hindi or Urdu. He was never completely at home speaking Hindi and still less Urdu.

As early as 1909 Gandhi wrote in his newsletter Hind Swaraj, "A universal language for India should be Hindi" (Ram Gopal 1966: 180). By 1917 the argument for Hindustani — a term carefully neutral between Hindi or Urdu - had become a constant in Gandhi's thinking and his political program. Gandhi defined Hindustani as "a resultant of Hindi and Urdu, neither highly Sanskritized nor highly Persianized or Arabianized" (R. King 1998: 82).

In speech after speech, editorial after editorial, from 1917 onward Gandhi hammered on the theme relentlessly, dismissing as trivial or unworthy the difficulties that enforcing Hindustani on the country as a whole might entail, riding roughshod over every iconic, emotional, or patriotic association speakers of other Indian languages might have. As for the script in which the Hindustani as national language should be written, he wavered between Devanagari and no choice at all (R. King 1998: 83).

Gandhi's tendency overall was to minimize the role of script. In a 1918 speech he laid out his thinking (Ram Gopal 1966: 186-187):

Hind[ustani] is that language which is spoken in the north by both Hindus and Muslims and which is written either in the Nagari or the Persian script. [It] is neither too Sanskritized nor too Persianized .... . The distinction made between Hindus and Muslims is unreal. The same unreality is found in the distinction between Hindi and Urdu .... There is no doubt or difficulty in regard to script. As things are, Muslims will patronize the Arabic script while Hindus will mostly use the Nagari script. Both scripts will therefore have to be accorded their due place. Officials must know both scripts.

Nehru, after Gandhi the major figure in the freedom movement, accepted Gandhi's advocacy of Hindustani as national language. The question of the script in which Hindustani was to be written was left completely open by both Gandhi and Nehru, and one understands why: to commit to one over the other was to take sides in the communal 
struggle between Hindu and Muslim, and that above all is what both Gandhi and Nehru were resolved not to do - which is why "Hindustani" became the preferred designation rather than "Urdu" (Muslim) or "Hindi" (Hindu). Those who favored the traditional Perso-Arabic script of Urdu were free to write in that; those who preferred the traditional Devanagari script of Hindi were free to use that. Better yet - this is the impression one forms - speak Hindustani, just do not write it.

But, as I wrote in my book on Nehru and language politics (R. King 1998: 84), this will not do, not in our all too imperfect world.

Communal hatreds between Muslims and Hindus cannot be simply wished away by pretending that the scripts used to write their language are devoid of evoked meaning. The power of language as icon must never be underestimated. Like it or not, the Urdu script means Muslim, the Devanagari script means Hindu. The Urdu script as seen by an angry, inflamed Hindu mob summons up talismanic images from the present and the past: cow-slaughter, temple-bashing, iconoclasm [Muslim destruction of Hindi sculptures], crescent and star, Aurangzeb [a seventeenth-century Mughal ruler hated by Hindus even today], green [the Muslim color]. When Hindus bent on doing violence to Muslims see a shop sign in Urdu, they want to smash it and burn that shop down. And viceversa. The Hindi script conveys to an enraged Muslim mob Vishnu and Shiva and a score of many-handed, many-headed gods and goddesses, cowdung, music before the mosque, dead pigs flung into mosques, Shivaji [a seventeenth-century Hindu Maratha leader hated by Muslims even today]. Old sins cast long shadows. Nowhere is this truer than in India's burning sun.

With the partition of India the worst of the Hindi-Urdu controversy passed into history. But not completely. There were terrible scenes of communal rioting in 1989 that followed upon the decision of the Uttar Pradesh government to make Urdu the second official language of the state. Hindi remained the official language of Uttar Pradesh as it always had been, but Muslims had fought for greater official recognition of themselves and their Islamic culture through recognition for their language, which was Urdu. Language was here as elsewhere a symbol — an icon - concealing a deeper perception of injury to ethnic/religious self-esteem.

It would be going too far to blame Hindi-Urdu digraphia for the partition of British India into the separate nations India and Pakistan; but it would not be going too far in the least to reify Hindi-Urdu digraphia as a metaphor for communal conflict between Hindus and Muslims on the subcontinent.

Hindi-Urdu, so typical a case of digraphia as a strictly linguistic concern, is typical too of the vast history of grief that underlies an 


\title{
$58 \quad$ R. D. King
}

innocuous linguistic exterior. Hence the title of this essay: the poisonous potency of script.

\author{
University of Texas, Austin
}

\section{Notes}

1. The earliest Sanskrit texts are known as the Vedas, the most famous of which is the Rigveda (Cardona 1987b: 448). The terms "Vedantic" and "Vedantism" refer to the philosophical system and world view taught by the Vedas - in effect a strain of Hinduism without the accretions of belief, such as the caste system, that came in through the teachings of later texts such as the Mahabharata and the Ramayana.

2. Khari Boli is more precisely [kharī bolī], and Madhyadeshi is [mədhyədešī]. But this degree of phonetic/phonemic detail seems to me unnecessary here as well as being a needless visual distraction, and so I shall dispense as much as possible with phonetic symbols and diacritic marks except where they are necessary to the exposition.

3. The phrase "Great Tradition" is due to the anthropologist and sociologist Robert Redfield, cf. Redfield (1967).

4. At partition in 1947 Pakistan was initially composed of West Pakistan and East Pakistan, formerly the predominantly Muslim northwest and northeast regions of British India. Only religion united the two parts; all else divided them: language, culture, geography. East Pakistan seceded from the federation in 1971 and became a separate nation, Bangladesh 'Land of the Bengali speakers'.

5. The term "communal" in the Indian context always has negative connotations. It is used to describe strife between different ethnic, caste, and religious groups: for example, Hindus and Muslims, Hindus and Sikhs, Untouchables and caste Hindus.

\section{References}

Cardona, George (1987a). Indo-Aryan languages. In The World's Major Languages, Bernard Comrie (ed.), 440-447. New York: Oxford University Press.

-(1987b). Sanskrit. In The World's Major Languages, Bernard Comrie (ed.), 448-469. New York: Oxford University Press.

Chatterji, S. K. (1969). Indo-Aryan and Hindi. Calcutta: K.L. Mukhopadhyay.

Das Gupta, Jyotirindra; and Gumperz, John J. (1968). Language, communication and control in north India. In Language Problems of Developing Nations, Joshua A. Fishman, Charles A. Ferguson, and Jyotirindra Das Gupta (eds.), 151-166. New York: Wiley.

Delacy, Richard (1998). Hindi and Urdu Phrasebook. Hawthorn, Australia: Lonely Planet.

Dittmer, Kerrin (1972). Die indischen Muslims und die Hindi-Urdu Kontroverse in den United Provinces. Wiesbaden: Otto Harrassowitz.

Kachru, Yamuna (1987). Hindi-Urdu. In The World's Major Languages, Bernard Comrie (ed.), 470-489. New York: Oxford University Press.

Kaplan, Robert D. (1999). Weakness in numbers. New York Times, October 18, A27.

Kelkar, Ashok (1968). Studies in Hindi-Urdu. Poona: Deccan College Postgraduate and Research Institute. 
King, Christopher R. (1994). One Language, Two Scripts: the Hindi Movement in Nineteenth Century North India. Bombay: Oxford University Press.

King, Robert D. (1998). Nehru and the Language Politics of India. Delhi: Oxford University Press.

Kulke, Hermann; and Rothermund, Dietmar (1993). A History of India. Calcutta: Rupa.

Ornstein, Jacob; and Gage, William W. (1964). The ABC's of Languages and Linguistics. Philadelphia: Chilton.

Rabin, Chaim (1971). Spelling reform - Israel 1968. In Can Language Be Planned? Joan Rubin and Björn H. Jernudd (eds.), 95-121. Honolulu: University Press of Hawaii.

Ram Gopal (1966). Linguistic Affairs of India. Bombay: Asia Publishing House.

Redfield, Robert (1967). The Little Community and Peasant Society and Culture. Chicago: University of Chicago Press.

Wolpert, Stanley (1993). A New History of India. New York: Oxford University Press. 